\title{
Self-managed abortion in urban Haiti: a mixed-methods study
}

\author{
Erin Nicole Berry-Bibee, ${ }^{1}$ Clotilde Josamine St Jean, ${ }^{2}$ \\ Nathan M Nickerson, ${ }^{2}$ Lisa B Haddad, ${ }^{1}$ Manuchca Marc Alcime, ${ }^{2}$ \\ Eva H Lathrop ${ }^{1}$
}

${ }^{1}$ Department of Gynecology and Obstetrics, Emory University, Atlanta, Georgia, USA ${ }^{2}$ Konbit Sante Cap Haitien Health Partnership, Portland, Maine, USA

\section{Correspondence to} Dr Erin Nicole Berry-Bibee, Department of Gynecology and Obstetrics, Emory University, Atlanta, GA 30303, USA; eberryb@emory.edu

Received 23 October 2017 Revised 8 May 2018 Accepted 9 May 2018 Published Online First 31 May 2018

\begin{abstract}
Objective Although illegal abortion is believed to be widely practised in Haiti, few data exist on such practices. We aimed to learn about illegal abortion access, methods, and perceived barriers to abortion-related care. Additionally, we aimed to identify the proportion of unscheduled antepartum visits to a public hospital that were attributable to unsafe abortion in Cap Haitien, Haiti.
\end{abstract}

Study design We conducted eight focus groups with women $(n=62)$ and 13 interviews with women's health providers and subsequently administered a survey to pregnant or recently pregnant women (20 weeks of gestation or less) presenting to the hospital from May 2013 to January 2014 ( $n=255)$.

Results Among the focus groups, there was widespread knowledge of misoprostol selfmanaged abortion. Women described use of multiple agents in combination with misoprostol. Men played key roles in abortion decisionmaking and in accessing misoprostol. Among the 255 pregnant or recently pregnant women surveyed, $61.2 \%(n=150)$ reported the current pregnancy was unintended and $30 \%$ $(n=78)$ reported attempting an induced abortion. The majority of women used misoprostol either alone or as a part of the medication/herb regimen for their self-managed abortion (85.1\%, $n=63$ ).

Conclusions Awareness of methods to induce abortion is high among women in urban Haiti and appears widely practised; yet knowledge of the safest self-managed abortion options remains incomplete. Access to safer abortion services could improve maternal health in Haiti.

\section{INTRODUCTION}

Unsafe abortion is a preventable public health crisis. ${ }^{12}$ Mortality from unsafe abortion ranges from 350 to 800 times greater than from safe abortion, depending on region of the world. ${ }^{13}$

\section{Key messages}

Healthcare providers and women in the community report that self-managed abortion is widely practised in urban Northern Haiti.

- Misoprostol is often used with a combination of other agents, some potentially harmful, for self-managed abortion.

- Men played key roles in abortion decision-making and in accessing misoprostol.

Globally, approximately half of all abortions are unsafe; an increasing trend, most notably in areas where abortion is illegal. ${ }^{2}$ Haemorrhage, sepsis, hypertensive disorders and unsafe abortion are the top four causes of maternal deaths worldwide. ${ }^{1}$ Researching abortion practices in regions where abortion is restricted and abortion safety is unknown can be crucial to inform efforts to reduce maternal mortality.

In Haiti, the maternal mortality rate is higher than in any other country in the Western hemisphere. ${ }^{4}$ Haiti's penal code forbids induced abortion in all cases with no explicit exceptions, making Haiti one of the most restrictive countries in the world. ${ }^{56}$ In a review of global abortion laws, researchers state that the law in Haiti is interpreted with the legal principle of 'necessity', which may provide a legal defence if an abortion is performed to save the life of the woman. ${ }^{5}$

Few data are available on abortion practices in Haiti. In the 2012 Demographic and Health Survey, 4\% of Haitian women reported ever having an induced abortion, ${ }^{7}$ yet, anecdotal evidence from local practitioners and US Agency for International Development (USAID) 
reports suggest that the abortion rate is significantly higher. ${ }^{18-10}$ Maternal morbidity and mortality from abortion in Haiti is unknown. In order to explore the effect that unsafe abortion has on maternal health, communities, and healthcare systems in Haiti we performed a mixed-methods study.

\section{METHODS}

The study took place from 15 May 2013 to 31 January 2014 at Justinian University Hospital (JUH), in Cap-Haitien, Haiti, in collaboration with Emory University (Atlanta, USA) and a non-governmental organisation, Konbit Sante Cap-Haitien Health Partnership (Maine, USA). Institutional review board approval for this study was obtained at both Emory and JUH. Cap-Haitien, the second largest city in Haiti, has one 300-bed public hospital (JUH) and several smaller health centres. Hospital Fort Saint Michel (FSM) is a small public health centre with a maternity unit that serves the poorest communal section in the city, Petite Anse.

\section{Qualitative methods}

Qualitative data collection consisted of in-depth interviews with women's healthcare informants and focus group discussions with women living in Petite Anse. Quantitative data collection consisted of a cross-sectional survey of pregnant women (29 July 2013 to 31 January 2014) presenting to JUH maternity ward for care. Before each phase of data collection, training sessions familiarised the research team with methodology, study guides and tools, and refreshed the principles of ethical research conduct using validated tools. ${ }^{11}$

Interview and focus group discussion guides consisted of open-ended questions and scenarios concerning pregnancy, contraception, and induced abortion. Community health workers based out of FSM used purposive and convenience sampling to recruit participants in Petite Anse (CJ). After verbal consent, three female Haitian research nurses facilitated focus group discussions in a private setting in each neighbourhood. Women at least 18 years of age, willing to participate, and able to speak Haitian Creole were eligible. We audiotaped all discussions then transcribed and translated them into English. After each group, we reviewed notes and transcripts for accuracy and discussed the themes that arose. We conducted focus group discussions until thematic saturation was reached as determined by team consensus.

Purposive sampling identified key women's healthcare informants which included community health workers, herbalists, traditional birth attendants, nurses and physicians (CJ and NN). After written consent, the primary author (EBB) conducted interviews in English with a translator as needed. Interviews were recorded and transcribed.
Qualitative analysis

The research team developed general concepts through review of notes. We developed a code book and two individuals (EBB and EL) independently read the transcripts and analysed them using the techniques of coding, memoing and sorting using Maxqda version 10 software (VERBI GmbH, Berlin). Discordance was resolved by re-review of transcripts (EBB and EL) and, if needed, review by a third person (LH). We used grounded theory to generate themes.

\section{Quantitative methods and analysis}

Results from the qualitative phase informed the development of a cross-sectional survey. At JUH, all women who are currently pregnant (regardless of gestational age) or recently pregnant (approximately $\leq 6$ weeks after the end of a pregnancy) and with an obstetric or gynaecological complaint are seen on the maternity ward at JUH and not in the general emergency room. We screened all women presenting to the JUH maternity ward over a 6-month period (July 2013 to Janurary 2014) for eligibility. Women were eligible if they were (1) self-reported $\leq 20$ weeks gestation or $\leq 6$ weeks post-pregnancy from a pregnancy $\leq 20$ weeks gestation; (2) $\geq 18$ years of age; and (3) a Haitian Creole speaker. After obtaining verbal consent, research nurses administered the survey verbally, recorded the answers and later entered then into an online database (FeedbackServer 5.4.1). We analysed survey data using SPSS version 22 (IBM, Armonk, NY, USA). Only women who answered our primary research question, 'Did you do or take anything to attempt an induced abortion in the current pregnancy?', were included. Current pregnancy is defined to include those within 6 weeks post-pregnancy for women presenting for care after spontaneous or induced abortion. We categorised all variables, and Chi squares were calculated comparing characteristics among women reporting and not reporting a self-managed abortion. For significant variables with three or more categories $P$ values were calculated from odds ratios and $95 \%$ confidence intervals.

\section{Patient involvement}

We sought feedback from women and healthcare workers in Cap Haitien from the onset to assist in selection of methodologies most appropriate for this sensitive topic, given women's priorities and preferences. At a meeting in Cap Haitien (March 2014), we presented findings to stakeholders and members of the public health community and collectively generated integrated themes and conclusions.

\section{RESULTS}

\section{Qualitative overview}

We conducted eight focus group discussions with a total of 62 women (mean 7.8 per group; range 6-9). The mean age was 28 (range 20-50) years and 
discussions lasted a mean of 105 (range 76-137) min. We conducted 13 interviews with women's healthcare informants; two gynaecologists, two gynaecology residents, three nurses, two community health workers, three traditional birth attendants and one herbalist. The interviews lasted a mean of 45 (range 24-67) min. Several prominent themes arose including abortion as a community norm, widespread knowledge of methods for self-managed abortion, and reliance on men to acquire misoprostol.

Focus group participants spoke freely about self-managed abortion practices in their communities. Use of misoprostol for self-managed abortion was widespread and was often combined with a potpourri of herbs and other remedies (eg, chloroquine, beer, seawater). Many women reported very specific regimens for self-managed abortion. One woman stated:

"[they] buy four tablets of Cytotec with a cold 'Fiesta" [a soda or soft drink], they put three in the Fiesta and one in their vagina. Some of them add Provera to the Cytotec. Others buy leaves like tobacco... There are many ways to throw baby [have an abortion]."

Another woman went on to explain:

"A friend told me to take leaves of pyeba and nim to drink with one Cytotec and put two Cytotec in the vagina...or they can use ti kole and boul de mas to drink with a bottle of beer and two tablets of ampicillin 500. Or they can take ginger with pepper with the beer."

Women, however, had incomplete understanding of which regimens were effective, dosages varied greatly, and they only sometimes identified misoprostol (as Cytotec) as a key agent. In addition, women had poor understanding of gestation limits or of risks by gestational age.

Access to misoprostol was often dependent on men purchasing it from street vendors: "I have heard that they don't sell Cytotec to women, often the men buy $i t$. In addition, the women spoke of men frequently playing dominant roles in the decision-making process of whether or not to have an abortion and if so, what method to use and how to procure it. One participant described: "He makes them [have the abortion], he buys pills and brings them to the girls".

Women reported 'poverty in Haiti', the need to conceal pregnancy from parents and the need to finish school as common reasons why women seek abortion. Women were aware of abortion via uterine instrumentation using hangers, curette instruments and/or sticks, but perceived this practice to be less common. Participants described several instances where unsafe abortion led to severe morbidity (eg, severe haemorrhage, bowel evisceration, hysterectomy) or death.

Healthcare informants all described self-managed abortion as widely practised in their communities. The non-physicians were reserved when discussing abortion, reported that they were not familiar with what specific methods were being used, and denied providing education to women seeking abortion information or services. Physicians reported commonly seeing many women for incomplete self-managed abortion after taking misoprostol and any combination of other remedies. They perceived unsafe abortion via uterine instrumentation to be less common than medication abortion and that second-trimester abortion occurred, but was less common than first-trimester abortion. Physicians reported haemorrhage and infection to be the most common post-abortion complications. The providers at the larger hospital, JUH, all reported recent stories of patients with septic and/ or hypovolemic shock due to self-managed abortion. Most physicians reported numerous personal experiences providing care for women who experienced severe morbidity or mortality due to unsafe abortion. However, they perceived that the more severe complications had occurred more commonly in years past, which they attributed to the increased use of misoprostol. Physicians identified limited resources, access to blood products in particular, as the biggest barrier to providing safer post-abortion care.

\section{Survey results}

During the study period 2716 current or recently pregnant (within 6 weeks post-pregnancy) women presented to JUH and, as anticipated, most women (88.1\%) presenting to JUH maternity ward were at advanced gestational age, often in active labour, and were therefore not eligible. However, 11.9\% $(n=323)$ met our inclusion criteria (figure 1). Of the eligible women, $81.9 \%$ were enrolled $(n=263)$. The primary reason for not enrolling was that women left the hospital prior to being approached $(n=36)$. One maternal death occurred in a woman estimated to be in her early second trimester due to maternal haemorrhage; additional details were unavailable. Of the 263 women enrolled, 97\% answered the primary research question, yielding 255 women for analysis (figure 1).

The unintended pregnancy rate among participants was $61.2 \%(n=150)$. Thirty percent of women reported having self-managed an abortion during the recently ended pregnancy $(n=78)$. Women who reported a self-managed abortion were more likely to be younger than 36 years old $(\mathrm{P}=0.001)$, have completed at least some secondary school $(\mathrm{P}=0.002)$, and be at less than 10 weeks gestation $(\mathrm{P}=0.003)$ compared with women who did not report self-managed abortion (table 1). In addition, women who reported a self-managed abortion in the current pregnancy were significantly more likely to be not married or living with their partner, have an unintended pregnancy, have had no prenatal care, and have attempted self-managed abortion in a previous pregnancy compared with women who did not report it (P values $\leq 0.001)$ (table 1$)$.

Among women reporting a self-managed abortion, $97.4 \%$ used medications and/or herbs $(n=76)$, one had 


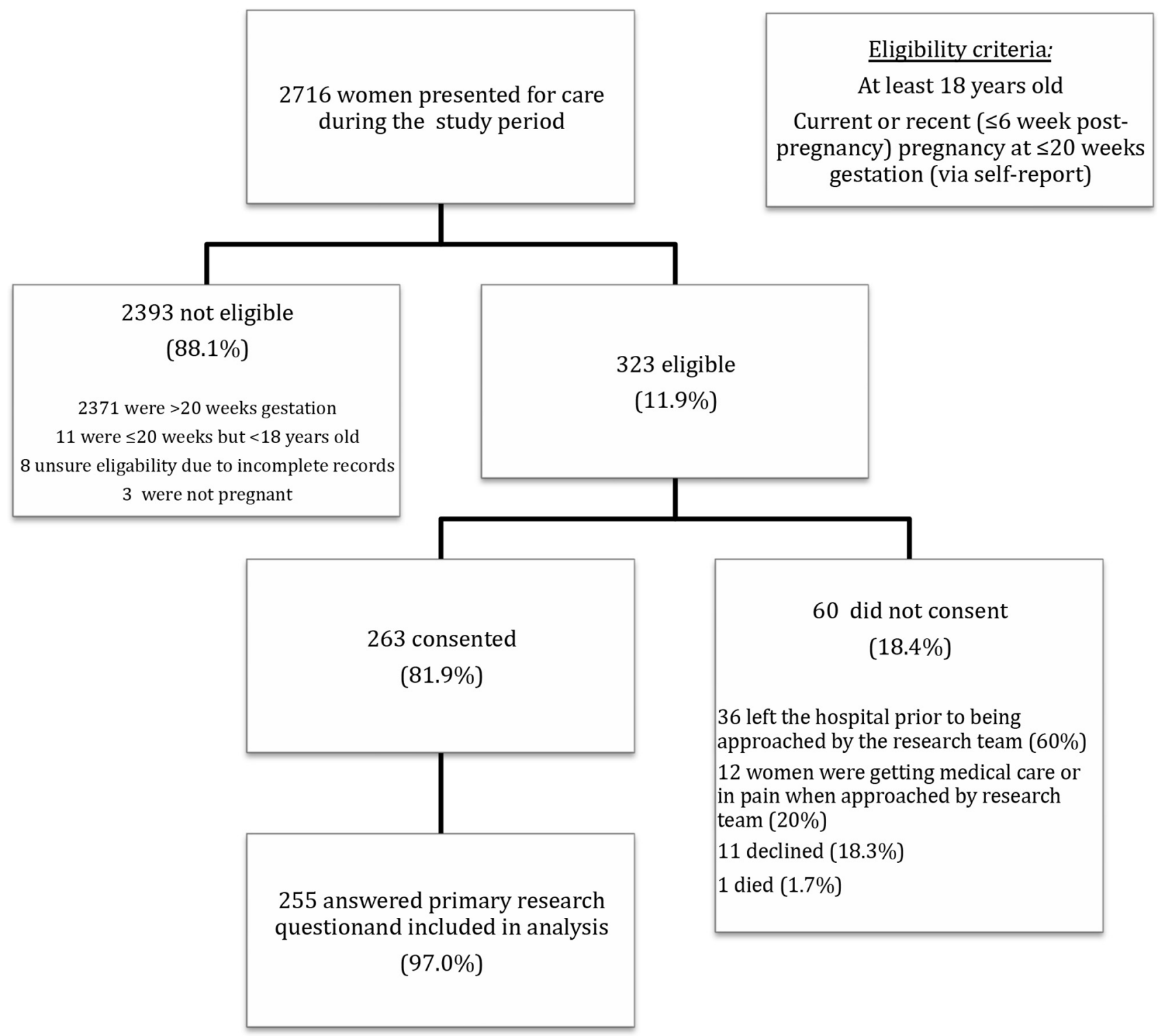

Figure 1 Outline of women presenting to Justinian University Hospital labour and delivery unit over the 6-month study period, July 2013 to January 2014.

a procedure and one did not report the method used. Among women using medications and/or herbs, 68 $(89.5 \%)$ reported which agent(s) were used; however, over $10 \%(n=8)$ did not know which agent(s) were used. The majority of women using medications and/or herbs for their self-managed abortions used multiple agents $(\mathrm{n}=41 ; 60.3 \%)$, with $32.4 \%$ using two agents $(n=22), 23.5 \%$ using three agents $(n=16)$ and $4.4 \%$ using four or more agents $(n=3)$. Misoprostol was used by nearly every woman who reported a self-managed abortion and who reported which agents she used $(n=63 ; 92.6 \%)$. The most common regimen for self-managed abortion with medication and/or herbs $(n=68)$ was misoprostol alone $(n=23 ; 33.8 \%)$ followed by misoprostol plus a common herb 'boul de mas' (+/-other) $(\mathrm{n}=22 ; 33.4 \%)$ and misoprostol plus beer $(\mathrm{n}=15 ; 22.1 \%)$ (table 2$)$.

Women did not report on how they took each individual agent but reported on the route of administration for the entire regimen. Of women who used a misoprostol-containing regimen, 92.1\% reported taking something orally $(\mathrm{n}=58), 84.1 \%$ reported taking something vaginally $(n=58)$ and $77.8 \%$ reported drinking a tea $(n=49)$, with $61.9 \%$ of women reporting using all three routes of administration $(n=39)$. The person who instructed the participants on how to do the abortion was most often their male partner $(n=38,48.7 \%)$ or a friend or family member $(n=14 ; 17.9 \%)$. Only two women reported that a medical professional gave them information on how to have an abortion.

\section{DISCUSSION}

Despite recent progress, the maternal mortality rate in Haiti remains high. ${ }^{4}$ This research suggests that self-managed medication abortion is widely practised in urban northern Haiti, though its contribution to maternal mortality or morbidity is unclear. Misoprostol use has decreased harm from self-managed 
Table 1 Characteristics of all survey participants and women who reported self-managed abortion in the current pregnancy compared with those who did not report a self-managed abortion

\begin{tabular}{|c|c|c|c|c|}
\hline Characteristics & $\begin{array}{l}\text { All survey } \\
\text { participants* }(n=255) \\
{[n(\%)]}\end{array}$ & $\begin{array}{l}\text { Participants who } \\
\text { reported self-managed } \\
\text { abortion }(n=78,30 \%) \\
{[n(\%)]}\end{array}$ & $\begin{array}{l}\text { Participants who did } \\
\text { not report a self- } \\
\text { managed abortion } \\
(\mathrm{n}=177,70 \%) \\
{[\mathrm{n}(\%)]}\end{array}$ & $\begin{array}{l}\mathrm{X}^{2} \\
\mathrm{P} \text { value }\end{array}$ \\
\hline \multicolumn{5}{|l|}{ Demographics } \\
\hline \multicolumn{5}{|l|}{ Age (years) } \\
\hline $18-24$ & $82(32.2)$ & $36(46.2)$ & $46(26.0)$ & 0.008 \\
\hline $25-35$ & $118(46.3)$ & $34(43.6)$ & $84(47.5)$ & 0.045 \\
\hline $36+$ & $55(21.6)$ & $8(10.3)$ & $47(26.6)$ & Ref. \\
\hline \multicolumn{5}{|l|}{ Relationship status } \\
\hline Married or living together & $155(61.0)$ & $35(44.9)$ & $120(68.2)$ & 0.000 \\
\hline $\begin{array}{l}\text { Single/divorced/widow/not living } \\
\text { together }\end{array}$ & $99(39.0)$ & $43(55.1)$ & $56(31.8)$ & \\
\hline Missing & 1 & 0 & 1 & \\
\hline \multicolumn{5}{|l|}{ Education } \\
\hline Completed primary school or less & $70(27.5)$ & $12(15.4)$ & $58(32.8)$ & Ref. \\
\hline Some secondary school & $161(63.1)$ & $61(78.2)$ & $100(56.5)$ & 0.002 \\
\hline Completed secondary school or beyond & $24(9.4)$ & $5(6.4)$ & $19(10.4)$ & 0.700 \\
\hline \multicolumn{5}{|l|}{ Pregnancy-related characteristics } \\
\hline \multicolumn{5}{|l|}{ First pregnancy } \\
\hline Yes & $60(23.5)$ & $22(28.2)$ & $38(21.5)$ & \\
\hline No & $195(76.5)$ & $56(71.8)$ & $139(78.5)$ & 0.243 \\
\hline \multicolumn{5}{|l|}{ Children (n) } \\
\hline 0 & $90(35.3)$ & $29(37.2)$ & $66(34.5)$ & 0.407 \\
\hline 1 & $66(25.9)$ & $20(25.6)$ & $46(26.0)$ & \\
\hline 2 & $47(18.4)$ & $10(12.8)$ & $37(20.9)$ & \\
\hline $3+$ & $52(20.4)$ & $19(24.4)$ & $33(18.6)$ & \\
\hline \multicolumn{5}{|l|}{ Unintended pregnancy } \\
\hline Yes & $150(61.2)$ & $71(92.2)$ & $79(47.0)$ & \\
\hline No & $95(38.8)$ & $6(7.8)$ & $89(53.0)$ & 0.000 \\
\hline Missing & 10 & 1 & 9 & \\
\hline \multicolumn{5}{|l|}{ Pregnancy resulted from: } \\
\hline Primary relationship & $217(85.4)$ & $62(80.5)$ & $155(87.6)$ & \\
\hline Secondary relationship & $37(14.6)$ & $15(19.5)$ & $22(12.4)$ & 0.143 \\
\hline Missing & 1 & 1 & 0 & \\
\hline \multicolumn{5}{|l|}{$\begin{array}{l}\text { Self-managed abortion in a previous } \\
\text { pregnancy }\end{array}$} \\
\hline Yes & $29(11.6)$ & $15(20.0)$ & $14(8.0)$ & Ref. \\
\hline No & $160(64.3)$ & $38(50.7)$ & $122(70.1)$ & 0.003 \\
\hline No previous pregnancy & $60(24.1)$ & $22(29.3)$ & $38(21.8)$ & \\
\hline Missing & 6 & 3 & 3 & \\
\hline \multicolumn{5}{|l|}{ Any prenatal care this pregnancy } \\
\hline Yes & $149(58.4)$ & $27(34.6)$ & $122(68.9)$ & 0.000 \\
\hline No & $106(41.6)$ & $51(65.4)$ & $55(31.1)$ & \\
\hline \multicolumn{5}{|l|}{ Contraceptive characteristics } \\
\hline Ever use of contraception & & & & \\
\hline
\end{tabular}


Table 1 Continued

\begin{tabular}{|c|c|c|c|c|}
\hline Characteristics & $\begin{array}{l}\text { All survey } \\
\text { participants* }(n=255) \\
{[n(\%)]}\end{array}$ & $\begin{array}{l}\text { Participants who } \\
\text { reported self-managed } \\
\text { abortion }(\mathrm{n}=78,30 \%) \\
{[\mathrm{n}(\%)]}\end{array}$ & $\begin{array}{l}\text { Participants who did } \\
\text { not report a self- } \\
\text { managed abortion } \\
(n=177,70 \%) \\
{[n(\%)]}\end{array}$ & $\begin{array}{l}X^{2} \\
P \text { value }\end{array}$ \\
\hline Yes & $128(50.4)$ & $41(52.6)$ & $87(49.4)$ & \\
\hline No & $126(49.6)$ & $37(47.4)$ & $89(50.6)$ & 0.645 \\
\hline Missing & 1 & & 1 & \\
\hline \multicolumn{5}{|c|}{$\begin{array}{l}\text { Use of a method of family planning when } \\
\text { became pregnant with current pregnancy }\end{array}$} \\
\hline Yes & $29(11.4)$ & $13(16.7)$ & $16(9.0)$ & \\
\hline No & $226(88.6)$ & $65(83.3)$ & $161(91.0)$ & 0.077 \\
\hline
\end{tabular}

*Survey participants were currently or recently pregnant women 20 weeks or less of gestation, at least 18 years old, and presenting to Justinian University hospital maternity ward for care. Ref., reference.

abortion in multiple settings globally, ${ }^{12-15}$ and this research suggests that the same may be occurring in Haiti. However, our findings indicate that women in this community still present with complications, such as haemorrhage and infection, after self-managed medication abortion. Our research identified several factors in this Haitian community that may contribute to complications from self-managed medication abortion, including incomplete awareness of the safest methods for self-management, reliance on male partners to obtain medications and an overburdened healthcare system.

Abortion stigma impacts women, providers and communities. ${ }^{16}$ Potentially as a result of stigma and secrecy, women in this community often depended on men for their abortions, ${ }^{16}{ }^{17}$ something that is not uncommon globally. ${ }^{18-20}$ Our findings suggest that women (and probably their male partners) had incomplete information about self-managed medication abortion which may have led to mis-dosing, combination with other, potentially harmful, agents and use beyond safe gestational age limits, potentially impacting abortion safety.

Table 2 Medication(s) used by women who reported a selfmanaged abortion via medication and/or herbs $(n=68)$

\begin{tabular}{ll}
\hline Medication(s) taken & $\mathbf{n}(\%)^{*}$ \\
\hline Misoprostol & $63(92.6)$ \\
\hline Misoprostol alone & $23(33.8)$ \\
\hline Misoprostol+boul de mas+/-other & $22(32.4)$ \\
\hline Misoprostol+beer & $15(22.1)$ \\
Misoprostol+chloroquine +/- other & $4(5.9)$ \\
Misoprostol+other & $2(2.9)$ \\
Boul de mas alone & $4(5.9)$ \\
Beer alone & $1(1.5)$ \\
\hline *Percentages may not add up to 100 due to multiple agents used by \\
women.
\end{tabular}

Globally, treating complications from unsafe abortion places significant financial burdens on public healthcare systems. ${ }^{21}$ Of all pregnant or recently pregnant women presenting for care at the maternity ward at JUH, 30\% came for post-abortion care, suggesting that treating complications from self-managed abortion places a significant burden on this facility. This added volume of patients places time constraints on busy providers, crowds already limited physical spaces, and consumes precious supplies. Abortion complications are largely preventable through the availability of safe abortion services, therefore safer abortion practices in Haiti could decrease the burden on the healthcare system. ${ }^{22}$

Globally, approximately $40 \%$ of all pregnancies are unintended. ${ }^{23}$ The population of surveyed women in this study, although not comparable to population-based surveys, had a high rate of unintended pregnancy at over $60 \%$. Total fertility rate in Haiti has decreased in recent decades, but remains significantly higher than the desired fertility rate, and the unmet need for family planning is $35 \% .^{7}$ Increased access to contraception can reduce unintended pregnancy and abortion, and in a setting in which abortion is unsafe yet widely practised, family planning programmes are critical to the efforts to reduce maternal mortality.

This research contributes to the limited literature available on abortion in Haiti. Utilising mixed methods, we captured observations of unsafe abortion in Haiti from different perspectives including women, local practitioners and women seeking post-abortion care. This study will lead to hypothesis generation for future studies and highlights areas to target for education efforts. While we surveyed the majority of eligible women, those not captured were often women needing urgent medical care, therefore we may have missed experiences of women using more dangerous methods to induce abortion. As abortion is stigmatised, underreporting may have led to an 
underestimation of the true burden of post-abortion care at JUH.

Harm reduction strategies aimed at making illegal self-managed abortion safer for women have improved outcomes for women in diverse settings. ${ }^{15} 24$ Public health efforts in Haiti should follow a model of harm reduction, including educating about the correct use of misoprostol, timely post-abortion care, and education on post-abortion contraception and should involve women, men, healthcare providers, pharmacists, and community leaders. However, complications from unsafe abortion will continue unless an effort is made to increase access to safer abortion services for all women.

Acknowledgements The authors would like to thank Youseline Telemaque, Sherlie Jean -Louis, Octave Junette and Roudelyne Mombremier and the other staff at the Justinian University Hospital for their dedication in conducting this research. They also thank the study participants.

Contributors All authors played a significant role in identifying and assessing the evidence and drafting and editing the manuscript. All authors approved the submission of this version of the manuscript.

Funding Funding for this work was received from the Society of Family Planning.

Competing interests None declared.

Patient consent Not required.

Ethics approval Emory University and Justinian University Hospital.

Provenance and peer review Not commissioned; externally peer reviewed.

(C) Article author(s) (or their employer(s) unless otherwise stated in the text of the article) 2018. All rights reserved. No commercial use is permitted unless otherwise expressly granted.

\section{REFERENCES}

1 World Health Organization. Unsafe abortion: global and regional estimates of the incidence of unsafe abortion and associated mortality in 2008. 6th edn. Geneva, Switzerland: World Health Organization, 2011.

2 Sedgh G, Singh S, Shah IH, et al. Induced abortion: incidence and trends worldwide from 1995 to 2008. Lancet 2012;379:625-32.

3 Grimes DA, Benson J, Singh S, et al. Unsafe abortion: the preventable pandemic. Lancet 2006;368:1908-19.

4 World Health Organization. Trends in maternal mortality: 1990 to 2015: estimates by WHO, UNICEF, UNFPA, World Bank Group and the United Nations Population Division. Geneva, Switzerland: World Health Organization, 2015.

5 Boland R, Katzive L. Developments in laws on induced abortion: 1998-2007. Int Fam Plan Perspect 2008;34:110-20.

6 Rights CFR. World abortion laws map, 2014.
7 Ministry of Public Health and Population [le Ministère de la Santé Publique and de la Population](MSPP) HCIlIHdlE, (IHE) and ICF International. 2012 Haiti Mortality, morbidity, and service utilization survey: key findings. Calverton, MD: MSPP, IHE, ICF International, 2013.

8 Coffman S. Bowel injury as a complication of induced abortion: a case report and literature review. Am Surg 2001;67:924-6.

9 Lathrop E, Telemaque Y, Goedken P, et al. Postpartum contraceptive needs in northern Haiti. Int J Gynaecol Obstet 2011;112:239-42.

10 USAID and Managment Sciences for Health. USAID/HAITI maternal and child health portfolio review and assessment, 2008.

11 RaBD R. Research ethics training curriculum. 2nd: Research Triangle Park NC USA Family Health International, 2009.

12 Miller S, Lehman T, Campbell M, et al. Misoprostol and declining abortion-related morbidity in Santo Domingo, Dominican Republic: a temporal association. BJOG 2005;112:1291-6.

13 Faúndes A, Santos LC, Carvalho M, et al. Post-abortion complications after interruption of pregnancy with misoprostol. Adv Contracept 1996;12:1-9.

14 Fiol V, Briozzo L, Labandera A, et al. Improving care of women at risk of unsafe abortion: implementing a risk-reduction model at the Uruguayan-Brazilian border. Int J Gynaecol Obstet 2012;118(Suppl 1):S21-7.

15 Briozzo L, Vidiella G, Rodríguez F, et al. A risk reduction strategy to prevent maternal deaths associated with unsafe abortion. Int J Gynaecol Obstet 2006;95:221-6.

16 Harris LH. Stigma and abortion complications in the United States. Obstet Gynecol 2012;120:1472-4.

17 Kumar A, Hessini L, Mitchell EM. Conceptualising abortion stigma. Cult Health Sex 2009;11:625-39.

18 Petitet PH, Ith L, Cockroft M, et al. Towards safe abortion access: an exploratory study of medical abortion in Cambodia. Reprod Health Matters 2015;22:47-55.

19 Biggs MA, Gould H, Foster DG. Understanding why women seek abortions in the US. BMC Womens Health 2013;13:29.

20 Chibber KS, Biggs MA, Roberts SC, et al. The role of intimate partners in women's reasons for seeking abortion. Womens Health Issues 2014;24:e131-e138.

21 Singh S, Darroch J, Ashford L. Adding it up: the costs and benefits of investing in sexual and reproductive health 2014. New York, NY: Guttmacher Institute, 2014.

22 World Health Organization. Safe abortion: technical and policy guidance for health systems. Geneva, Switzerland: WHO, 2012.

23 Sedgh G, Singh S, Hussain R. Intended and unintended pregnancies worldwide in 2012 and recent trends. Stud Fam Plann 2014;45:301-14.

24 Hyman A, Blanchard K, Coeytaux F, et al. Misoprostol in women's hands: a harm reduction strategy for unsafe abortion. Contraception 2013;87:128-30. 